\title{
What Experience Cannot Teach Us About Time
}

\author{
Akiko M. Frischhut
}

Published online: 18 October 2013

(C) Springer Science+Business Media Dordrecht 2013

\begin{abstract}
Does the A-theory have an intuitive advantage over the B-theory? Many A-theorists have claimed so, arguing that their theory has a much better explanation for the fact that we all experience the passage of time: we experience time as passing because time really does pass. In this paper I expose and reject the argument behind the A-theorist's claim. I argue that all parties have conceded far too easily that there is an experience that needs explaining in the first place. For what exactly is an experience of temporal passage? One natural thought is that we experience passage in virtue of experiencing change, or in virtue of experiencing change as 'dynamic'. Another is that we experience passage in virtue of experiencing events as (successively) present. None of these experiences, I argue, amounts to an experience of passage. Although there might still be other ways to experience passage, A-theorists would have to provide us with a plausible candidate experience. If there is such an experience at all, it won't be one that qualifies as what we intuitively take to be an experience of passage. The 'intuitive advantage', it seems, has dissolved in any case.
\end{abstract}

Keywords A-theory - B-theory - Temporal passage . Experience of time - Experience of temporal passage . Temporal perception $\cdot$ Change $\cdot$ Presentness

\footnotetext{
A. M. Frischhut ( $\square)$

Department of Philosophy, University of Geneva, rue de Candolle 2, 1211 Genevea 4, Switzerland e-mail: akiko.frischhut@gmail.com

A. M. Frischhut

Subject of Philosophy, University of Tubingen, Philosophisches

Seminar, Bursagasse 1, 72020 Tübingen, Germany
}

\section{Introduction}

Time, it seems to us, passes, flows, flies or crawls. Days end, months change, years go by. Few things seem as sure to us in everyday life as the continuous passage of time. Although there are many metaphysical and semantic arguments that intend to show that time passes, one of the most persistent and powerful arguments comes from a very different angle. ${ }^{1}$ It is an intuitive argument that draws on our everyday experiences. The argument is that passage is 'given' to us in experience. The experience of temporal passage is a fundamental aspect of our lives and the best explanation for these experiences is simply that time really passes. Or so it seems.

The idea that we can infer time's passage from experience plays a major role in the debate between dynamic accounts of time, which hold that time really does pass, in the sense that temporal passage is an objective feature of reality, and static accounts which deny that there is anything in reality that corresponds to the concept of temporal passage. A first intuitive characterisation of what we mean when we talk about temporal passage could be given as follows: what is future will be present, what is present will be past and what is past was once present. ${ }^{2} A$-theories and tense realist theories are paradigm cases of dynamic

\footnotetext{
1 Among others, there is the classic argument that change requires temporal passage, inspired by McTaggart's view (1908, 1927) (although McTaggart ultimately rejects temporal passage). Some may argue that temporal passage is reflected in the tensed structure of language. A further argument is found in Prior's paper 'Thank Goodness That's Over' (1959), where he argues that we need the passage of time to make sense of our emotional attitudes towards events.

${ }^{2}$ Not all dynamic theories would be entirely happy with this characterisation but it suffices to give a first intuitive grasp of the phenomenon I am concerned with.
} 
theories of time. ${ }^{3}$ Static accounts of time, like the B-theory, reject the idea that time passes, no matter how passage is characterised. $^{4}$ Time, on this view, is a fixed, static dimension. It does not flow, just as space does not flow. Both parties, dynamic and static alike, standardly accept the idea that we have experiences as of passage. ${ }^{5}$

That we experience the passage of time is an assumption that is not only shared by all of us when we go about our daily lives, but it is also embraced by the overwhelming majority of theoreticians, historical and contemporary alike. Here is a selection of some characteristic quotes from the literature:

1. In practice, the most influential argument in favour of the objective present and the objective flow of time rests on an appeal to psychology- to our experience of time. It seems to us that time flows, the argument runs, and surely the most reasonable explanation of this is that there is some genuine movement of time which we experience, or in which we partake. (Price 1997, pp. 14-5).

2. Let me begin this inquiry with the simple but fundamental fact that the flow of time, or passage, as it is known, is given in experience, that it is as indubitable an aspect of our perception of the world as the sights and sounds that come in upon us (...). (Schuster 1986, p. 695).

3. The final motive for the attempt to consummate the fourth dimension of the manifold with the special perfection of passage is the vaguest but the most substantial and incorrigible. It is simply that we find passage, that we are immediately and poignantly involved in the jerk and whoosh of process, the felt flow of one moment into the next. Here is the focus of being. Here is the shore whence the youngster watches the golden mornings swing toward him like serried bright breakers from the ocean of the future. Here is

\footnotetext{
${ }^{3}$ For defence of the A-theory and tense realism see among others: Bigelow (1996), Broad (1938), Markosian (2004), Smith (1993), Schlesinger (1991), Zimmerman (2005), Crisp (2005, 2007), Prior (1958, 1967, 1968a, b), Tallant (2009, 2010, forthcoming), Zeilicovici (1981). For the distinction between tense realism and A-theory see (Percival 2002).

${ }^{4}$ B-theorists include Le Poidevin (1996, 1998), Le Poidevin and Mellor 1987), Mellor (1981, 1998), Oaklander (1991, 1993, 2002, 2004), Quine (1960), Reichenbach (1947), Russell (1914, 1940, 1948), Smart (1949, 1955), Smith (1993), Williams (1951). Not all B-theorists think of themselves as static theorists. Oaklander (2012) and Maudlin (2002) defend a B-theoretic account of temporal passage according to which time is inherently dynamic just by virtue of the fact that it features a sequence of different events (Oaklander) and/or has a privileged direction (Maudlin). This is not the sense of passage the dynamic theorist has in mind.

5 To my mind, the only philosophers who have denied that we experience temporal passage (although for different reasons than me) are Prosser $(2012,2007)$ and Deng. Dainton comes close to arguing that we do not experience passage in (Dainton 2011).
}

the flood on which the oldster wakes in the night to shudder at its swollen black torrent cascading him into the abyss (Williams 1951, pp. 465-6).

4. Above and beyond and before all these considerations, of course, is the manifest fact that the world is given to us as changing, and time as passing... all the philosophizing in the world will not convince us that these facts are mere illusions (...) In sum then, it is a central aspect of our basic picture of the world that time passes, and that in virtue of that passage things change. (Maudlin 2007, p. 135).

No doubt the intuition is compelling; but it is dangerous to give into the temptation of accepting it too quickly. Appearances are deceptive. It is in fact far from obvious that we can have experiences as of temporal passage, at least when the experiences are supposed to support our belief that time passes. First of all, I will argue that only experiences in the strict sense, that is, perceptual experiences, can succeed in the role of securing the dynamic theory an intuitive advantage over the static one. Then I shall look at three candidate experiences that people usually mention when it comes to specifying what an experience of passage is supposed to be. None of them, I argue, do in fact amount to an experience of passage. Worse, we could not even infer that time passes from them. Granted, there might be other ways to experience passage - but if I am correct, then it is at least not evident that we experience passage. Adherents of dynamic accounts of time would have to do much more work explaining what it is to experience temporal passage and how experience is supposed to support the notion of temporal passage. This would weaken their alleged intuitive advantage considerably. The rest of this paper is divided into four sections. In section two I introduce the argument behind the claim that we can know passage from experience. The best way to resist it, I claim, is to deny that we have experiences as of passage. I then assess three usual suspects that have been suggested as experiences of temporal passage. I begin in section three with the "folk intuition" that we experience passage by virtue of experiencing change. This intuition, I argue, is false because we could have experiences of change in a world where time does not pass. In section four I evaluate a slightly different thesis, namely that we are experientially aware of temporal passage by virtue of undergoing change experiences with a distinctively dynamic character, especially when contrasted with experiences of spatial variation. I argue that the "dynamic feel" cannot give us any indication as to whether time passes or not. In the fifth and last section I reject the idea that we experience passage by virtue of experiencing events as successively present.

Before I begin, I should mention two caveats. First, I shall assume that perceptual experiences have representational contents, where the contents of one's experiences 
'represent the world as being a certain way' (Peacocke 1992, p. 61). The view I am assuming is a weak content view, which is compatible with, but does not entail the stronger thesis that perceptual content is propositional. Thus understood, the view that experiences have contents is widely supported in contemporary debates about perceptual experiences (cf. Siegel 2010, p. 27). Secondly, I shall concentrate only on visual experiences. ${ }^{6}$ I believe, however, that my argument is sufficiently general to be applicable to other sensory modalities.

\section{The Argument from Experience}

The quotations above express the intuition that the experience of time's passage is one of the most fundamental and certain human experiences, above and beyond any reasonable doubt. The intuition is that it seems to us as if time passes and this seeming is so undeniable and figures so prominently in our everyday life that, avoiding the conclusion that we are deeply deluded creatures, we ought to make room for passage as an objective feature of the world. The argument implied in the quotations can be summarised with what I will call with Le Poidevin (2007, p. 77) the 'Argument from Experience', from here on AfE. ${ }^{7}$ In its most simple form, AfE can be expressed as follows:

(AfE):

1. All of us constantly experience time as passing.

2. The best explanation for these experiences is that time really does pass.

3. Therefore time passes.

Premise one expresses the intuition that passage is represented in our experience and that we have these experiences all the time. The idea is that experiences of temporal passage are not only had by some of us, sometimes, but by all of us, always. Premise two claims that the experience is best explained as an experience of some genuine feature in the world. The conclusion is supposed to be an inference to the best explanation. Supposedly the idea is that we know that the first premise is true just by introspection. Given the ubiquity of the experience in question, it is more plausible to think of passage experiences as veridical, than to think of them as illusory. From there, we make an inference to the best explanation to get to the conclusion, where the general principle employed is of the form 'if $p$ is the best explanation for $\mathrm{q}$, and $\mathrm{q}$, then $\mathrm{p}$ '.

\footnotetext{
${ }^{6}$ I will sometimes use 'experience' as a shorthand for 'visual perceptual experience'.

${ }^{7}$ Le Poidevin's argument actually refers to a bundle of arguments. I have taken his label to identify what I take to be the most important one.
}

There are three different ways to object to AfE. One is to deny that the fact that time passes follows from it's being the best explanation for our experience. This would be simply to reject the principle from inference to the best explanation. I shall assume that the principle is true. The second way is to reject premise two. Rejecting the second premise is to doubt whether the fact that time passes best explains our experience of temporal passage. ${ }^{8}$ If, for example, our experiences of passage were illusions, or hallucinations, then the fact that we undergo these experiences would not be best explained by the fact that time passes. To deny the veridicality of the experiences in question is the most popular strategy among static theorists, standardly the B-theorists. ${ }^{9}$ Popular it may be but it is not the best strategy for the B-theorist, as it puts her in an uncomfortable position. By accepting the assumption that we experience temporal passage, the B-theorist is forced to declare an allegedly fundamental feature of experience as illusory. The onus seems to be on her to explain why and how it is that we all suffer from the illusion of temporal passage. Finally, the third and best way to object to AfE is to deny that we have experiences (as) of temporal passage. It deprives the A-theory of its alleged intuitive advantage and blocks the inference to the best explanation. If there are no experiences to be explained in the first place, then the argument cannot get off the ground. As a result, the B-theorist never has to argue from the defensive corner in the first place. In the attempt to resist AfE, this strategy has been curiously underexplored. Presumably the reason is that most people find the idea that we experience passage so intuitively compelling that they do not waste much thought on whether it is actually true. I shall argue, however, that this is a mistake because if we think carefully about what it would mean to experience temporal passage, it is not obvious at all that we do.

For the rest of this paper I will pursue the last strategy against AfE. I will argue that at least none of the standard candidate experiences normally put forward as experiences of passage amounts to an experience of passage. A great part of the challenge consists in clarifying AfE, for as long as we do not know what it means to have an experience of passage and how we could infer from it that time passes, it is far from obvious how the argument is supposed to work. I begin in the next section with the "ordinary folk

\footnotetext{
8 The objection can also be understood in a more general way. The doubt then seems to be whether we can, in principle, ever know whether a certain explanation is the best explanation for some explanandum. But although we might strictly speaking never be in the position to know whether an explanation is really the best explanation, it does not mean that it could not actually be the best explanation. My thanks to Fiona Macpherson who brought my attention to this point.

9 Philosophers who have argued along these lines include Le Poidevin (1991), Oaklander (1993), Mellor (1998), and Paul (2010).
} 
intuition" according to which we experience passage by virtue of experiencing ordinary change.

\section{An Ordinary Folk Intuition}

It is a very natural thought to many that we simply experience time's passage whenever we experience change. Here is how Le Poidevin puts it:

As for the passage of time, we are not only aware of this when we reflect on our memories of what has happened. We just see time passing in front of us, in the movement of a second hand around a clock, or the falling of sand through an hourglass, or indeed any motion or change at all (Le Poidevin 2007, p. 76). ${ }^{10}$

The idea appears to be that we 'just see' passage in the moving of the clock's hand, because passage looks like ordinary change in visual experience. ${ }^{11}$ Intuitive support for this view seems to come from the thought that we measure how much time passes when we observe the length of time that it takes for a change to occur. After all we say things like

'Two hours have passed since I put the roast in the oven, it is done now' or

'Time seems to pass very quickly when you are reading a gripping novel'.

Such a view is based on confusion though. Both statements do not refer to anything but the duration of time it takes for some change to occur. The first one merely states that it took two hours for the roast to cook; the second one states that the length of time it takes to read a novel appears shorter than it is, when it is a gripping story. There is nothing in these statements which refers uniquely to temporal passage and which is not applicable to mere change or duration without temporal passage. Although it might be true that experiences of change motivate us to believe that time passes, we do not experience passage in experiencing change. Moreover, we cannot infer temporal passage from our experience of change. To think otherwise, is to confuse passage with duration. Or so I shall argue.

\footnotetext{
${ }^{10}$ Le Poidevin does not defend the view-he is merely describing an intuitive pre-philosophical assumption that most of us share.

11 By 'ordinary change' I mean all changes that objects can undergo apart from the change that constitutes temporal passage. When I just say 'change' I refer to ordinary change, unless otherwise indicated. I am not implying that all ordinary changes can be perceived. Mere Cambridge changes are presumably not perceivable and that they are included under the label 'ordinary change' might sound strange. However, the term 'ordinary change' is mainly chosen to separate the change that uniquely constitutes temporal passage from all other changes.
}

To begin with, when considered carefully the idea that we experience time's passage by virtue of experiencing change appears to be motivated by three implicit assumptions. First, the assumption that we have experiences of change. Apparently innocent this is in fact a controversial thesis, highly debated in the philosophy of temporal perception. Second, the assumption that change entails temporal passage. I aim to show that this is false. And third, the assumption that if $\mathrm{p}$ entails $\mathrm{q}$, then experiencing that $\mathrm{p}$ entails experiencing that $\mathrm{q}$. This again is very controversial and requires at least some qualification. I shall argue that even if we accepted the first and third assumption, the argument still fails because change does not entail passage. Experiencing ordinary change does not amount to experiencing passage, for we could have accurate experiences of ordinary change, even if time did not pass. Let me go through the assumptions one by one, starting with the first one.

Although our awareness of change and duration seems obvious, the analysis of temporal experience encounters an intricate problem. The problem is that temporal phenomena such as change and duration take time, while our perceptual experiences seem confined to the momentary present. ${ }^{12}$ If our perceptual awareness lacks temporal depth though, then it is impossible for us to perceptually experience change (or any temporally extended structure). This problem is well known in the literature as 'paradox of temporal awareness' (Dainton 2010).

Initially it might not be entirely clear what the problem is about. One might for example think that to experience change, as for example the change of a chameleon from red to green, is to see that the chameleon is green, remember that it was red and thereby be aware of the chameleon's change-but in that case one would not perceptually experience the change of the chameleon. One would infer that the chameleon has changed from memory and experience. Or one might think that to experience change is to be in a composite mental state constituted by a perceptual experience with the content 'the chameleon is green' and a memory state with the content 'the chameleon was red', where the combination of both results in an experience of

\footnotetext{
12 Strictly speaking it is not true that we only perceive what is momentarily present. In fact, all we ever perceive is the past, due to the time lag in perceptual experience. The point is, however, that we only ever perceive what was present, but we do not perceive more than what was present at the time when the light was emitted from the object we are currently perceiving. Our awareness, it seems, is restricted to what happens at a time, and cannot 'take in' what occurs over time. It is natural to assume that when a perceptual stimulus takes $n$ seconds to reach us at a time $t$, then we are perceptually aware of what happens at time $t-n$, but not of anything that happened before or after $t-n$. For ease of reading I shall stick with the less precise formulation that we are only ever perceptually aware of what is present.
} 
change. Alternatively one might think that one could judge that the chameleon was red, while perceiving that it is green or imagine that it was red, while perceiving that it is green, where in both cases the combination of the imaginative state, or the judgement with the perceptual state would result in an experience of change. These kind of more "loosely understood" experiences are not at issue here. Nobody doubts that we are in some way aware of (ordinary) change. The dispute in the debate about temporal perception is whether one can be aware of change solely by virtue of one's current perceptual experience. The initial problem thus persists: if we are only ever perceptually aware of what is (or more precisely was) momentarily present, and change and duration are temporally extended phenomena, then we cannot be perceptually aware of change (or any other temporally extended phenomena).

For some theorists, the lesson to learn from the paradox is to deny that we can, strictly speaking, ever have perceptual experiences of change. ${ }^{13}$ Note, however, that these sceptics about change perception cannot argue in terms of AfE. If my experience of change was a composite of my perceptual experience that $\mathrm{F}(a)$ and my remembering or imagining that $\mathrm{G}(a)$, I would not be experientially aware of change or passage. I could only infer that change has occurred and thus only infer that time has passed. But if we are merely inferring that time passes, it is unclear what the intuitive advantage of dynamic theories amounts to. After all, static theorists get to their conclusion also by means of inference. It is thus particularly important to keep in mind that AfE appeals to strictly perceptual experiences only. It is only because AfE is based on a claim about perceptual experiences that its defenders can claim an intuitive advantage over static theorists: this, in fact, must be the unique appeal of the argument. AfE cannot be entirely neutral about the question whether or not we perceive change. Its defenders must seek support from accounts that argue that we can, strictly speaking, experience change. These specious present accounts typically make room for change experiences by allowing individual experiences to represent short periods of time. ${ }^{14}$ The first assumption then, comes at a price: those who hold it must accept some kind of specious present theory according to which a single perceptual experience can represent a temporally extended structure such as change.

\footnotetext{
13 Philosophers who have denied that we can, strictly speaking, have perceptual experiences of change include Mabbott (1951, 1955), Dennett (1991), Mellor (1998), Le Poidevin (2007), Kelly (2005), and Plumer (1985).

${ }^{14}$ Specious present theories of various types have been among others defended by James (1890), Broad (1938), Foster (1982), Dainton (2000) and Tye (2003). For a good overview of the temporal perception debate, see Dainton (2008).
}

For the folk intuitionist this might still be an affordable price. Fair enough. More troublesome, however, is the idea that experiencing change entails experiencing time's passage. This is problematic, for it depends on two highly problematic claims: on the second assumption, according to which change entails passage, and on the third, which is that if $\mathrm{p}$ entails $\mathrm{q}$, then experiencing that $\mathrm{p}$ entails experiencing that q. Let us start with the latter one. Suppose that two concepts 'p' and 'q' are connected when they are such that 'p' entails ' $q$ ', and that when we acquire the concept of 'p', we thereby acquire the concept of ' $q$ '. ${ }^{15}$ It does not follow then from the connection of 'p' and ' $q$ ' that whenever $\mathrm{p}$ is experienced, $\mathrm{q}$ is experienced. A subject possessing the concepts ' $\mathrm{p}$ ' and ' $\mathrm{q}$ ' might perceive $\mathrm{q}$ whenever they perceive $\mathrm{p}$, but they might not experience that $\mathrm{q}$ whenever they experience that $\mathrm{p}$ (and thus could not form the belief that q) because they might apply the concepts independently in experience. For example, somebody might possess the concept of a triangle, and the concept of a geometrical figure, but not experience that there is a geometrical figure, when they experience that there is a triangle. So even if a subject possessed the concepts of 'change' and 'temporal passage', and those concepts were connected, it does not straightforwardly follow that they would experience passage whenever they experienced change. Admittedly though, it is plausible enough to assume that if 'change' and 'temporal passage' were connected in that way, and a subject would be in possession of both concepts, they would at least be in the optimal position to experience passage whenever they experienced change. ${ }^{16}$

For the sake of the argument let us assume that if change and passage were connected, a subject would experience that time passes whenever they experienced that change occurs. Then the correctness of the folk intuition (the intuition that we experience passage by virtue of experiencing change) would depend on whether the two concepts are in fact connected, which in turn (it seems plausible enough) depends on whether change entails passage or not. I shall argue that this is not the case, and that the folk intuition thus fails.

Metaphysically speaking, change occurs if some object $a$ is $\mathrm{F}$ at $\mathrm{t}_{1}$ and $\mathrm{G}$ at $\mathrm{t}_{2}$ where $\mathrm{F}$ and $\mathrm{G}$ are incompatible properties. Such a change in some object is related to a change of atomic events: $a$ changes from $\mathrm{F}$ at $\mathrm{t}_{1}$ to $\mathrm{G}$ at $\mathrm{t}_{2}$, if there is a change from event $\mathrm{E}_{1}\left(\mathrm{~F} a\right.$ at $\left.\mathrm{t}_{1}\right)$ to $\mathrm{E}_{2}\left(\mathrm{G} a\right.$ at $\left.\mathrm{t}_{2}\right)$. Qualitative change requires a succession of events which differ with respect to the properties or objects involved. (Merely) quantitative change requires a succession of

\footnotetext{
15 The term 'connected' has been suggested to me by Craig French. ${ }^{16} \mathrm{I}$ am much indebted to Thomas Brouwer and Craig French for discussion on this point.
} 
events which differ only with respect to the times at which the events occur. ${ }^{17}$ The difference between change in a dynamic world and change in a static world is that the former change is tensed, and the latter is not. If time passes, then change occurs if and only if $\mathrm{F}(a)$ is past (and was present) and $\mathrm{G}(a)$ is present (and was future). If time doesn't pass, then change occurs if and only if $a$ is tenselessly $\mathrm{F}$ at $\mathrm{t}_{1}$ and tenselessly $\mathrm{G}$ at $\mathrm{t}_{2}$. I shall call the former $A$-change, and the latter $B$-change. If time passes, then all change is A-change, as A-change is necessitated by temporal passage. If time does not pass, then all change is B-change. Note however that the most general definition of change, according to which change occurs if $\mathrm{F}(a)$ at $\mathrm{t}_{1}$ and $\mathrm{G}(a)$ at $\mathrm{t}_{2}$, applies to all types of change and is prima facie neutral as to whether time passes or not. Both types of change, $\mathrm{A}$ and $\mathrm{B}$, involve a succession of at least two events, in the case of qualitative change $\mathrm{E}_{1}\left(\mathrm{~F} a\right.$ at $\left.\mathrm{t}_{1}\right)$ and $\mathrm{E}_{2}$ $\left(\mathrm{G} a\right.$ at $\left.\mathrm{t}_{2}\right) .{ }^{18}$ Thus the fact that things change does not entail the fact that time passes.

How do we get from here back to the experience of change and passage? To experience ordinary change just is to experience a succession of qualitatively distinct events. ${ }^{19}$ In other words, change looks like one thing happening after the other in experience. When we see a chameleon changing from red to green for example, we see that change as a succession of two events, first an event 'chameleon-being-red', followed by another event 'chameleon-being-green'. A succession takes time. It comes at no surprise that one is aware of duration when one is aware of change and succession. In other words, we experience time when we experience change in objects, which is manifest in the fact that we measure durations of time by observing change. ${ }^{20}$ I suspect that this might be the confusion behind the ordinary folk intuition that we experience

\footnotetext{
17 All qualitatively distinct events are also numerically distinct, although the converse does not necessarily hold.

18 Standardly, change is taken to occur over time, but some people think that changes are instantaneous (Priest 2006). However, even if change was instantaneous, it could not occur in a world without duration. If there is nothing that changes, nothing that is different now from how it was before, there cannot be change. Moreover, even if change was instantaneous, we would not experience it as instantaneous. When a traffic light changes from red to green, for example, we do not experience that the light is simultaneously red and green, we experience that the light is first red and then green, that is, we experience the change as occurring over time. In experience, $a$ 's change from $\mathrm{F}$ to $\mathrm{G}$ always takes time, whether or not there is a moment of change. Note however that this does not imply that our experiences would be illusory if Priest was correct.

19 Although change looks like succession in experience, not all successions look like change. To experience succession $a s$ change, at least the properties or the objects constitutive of the successive events must differ. A mere numerical change of events cannot be experienced as change, which is presumably why it is standardly thought that we could not be aware of time without being aware of (at least mental) change.
}

temporal passage when we experience change. For the same is not true in the case of passage: neither the fact that things succeed each other, nor the fact that some things take time entails that time passes. Therefore, we could have accurate experiences of change, even if time did not pass. To experience temporal passage by virtue of experiencing change, a subject would have to experience A-change as Achange, rather than B-change, for A-change (as opposed to B-change) only occurs if time passes. In other words, for the folk intuition to be correct, a subject's experience of change would have to consist in more than simply experiencing $\mathrm{F}(a)$ at $\mathrm{t}_{1}$ and $\mathrm{G}(a)$ at $\mathrm{t}_{2}$. The folk intuition however, is just that we experience passage by virtue of experiencing change, not the intuition that we experience passage by virtue of experiencing A-change rather than B-change. Although some A-theorists do argue along these lines, it should be noted that this is a different argument altogether. ${ }^{21}$ Our every day experience of change is silent as to whether time passes or not.

Here is another way to put it. Just as we (standardly) occupy various spatial perspectives during our lives, we occupy various temporal perspectives during the course of our lives. Throughout our lifetime we are aware of what happens at different times, at different times - that is to say, we are aware of one time after another. But this change of temporal perspective can be explained dynamically as well as statically. Explained dynamically, our being aware of one time after another is in some sense "brought about" by time "moving" or "passing by", that is, by the fact that time passes. Explained statically, we "move" through time, changing our temporal perspectives, one by one, in a similar way as we are moving through static space, thereby changing our spatial perspectives.

Consider an analogy that might hopefully help to illustrate the distinction I have in mind. Imagine you are visiting some art exhibition and you are led into a dark room with a hole in the wall to look through. Looking through the hole, you can see an image projected on another wall. After a while the image disappears and is replaced by another one, which is replaced again after a few seconds. Ten images are presented to you in this way before the slide show is over and you are shown into another room. The second room is also dark, but instead of one hole in the wall opposite the door, there are ten holes, lined up in a row. A little note tells you to look into each of the holes, one by one, starting with the first one on the left. As you look into the holes, one by one, you can see the very same

\footnotetext{
${ }^{20}$ See also Shoemaker for this point (1969). Shoemaker thinks that the fact that we measure time by observing change makes it plausible that there cannot be time without change, for to hold otherwise is to be sceptic about the possibility of measuring time at all. Whether or not there could be time without change shall not be my concern here. ${ }^{21}$ I come back to this in $\S 5$.
} 
images that you have just seen in the slide show. There is no difference in what you see between the first room and the second room. In both rooms you see a succession of different images, one by one, only that in the first room you are still, and the images slide past you, where in the second room the images are still and you are changing your visual perspective, thereby seeing the different images. In any case, just from what you have seen, you cannot tell whether it is you that moves, or whether the images slide by.

This is of course not a perfect analogy, but the idea should be clear enough. The difference between the slide show of images and the row of images is somewhat analogous to the difference between change in a dynamic world, and change in a static world. The analogy is certainly not ideal because it is misleading to speak about "our movement through time" in the same way as we speak about our movement through space. For the B-theorist, "movement" through time consists in our occupying various temporal perspectives, simply by virtue of existing at different times. For the A-theorist, our occupying multiple temporal perspectives is necessitated by the passage of time. Common to both cases is that we cannot distinguish between the two kinds of succession, just by experiencing one thing after the next. Thus the experience of ordinary change cannot tell us whether it is time itself that "moves" (as with the slide show) or whether we just see different things at different times (as with the row of images). I conclude that the idea that we experience passage by virtue of experiencing change, or that we can infer passage from experiencing change, is based on a confusion between passage on the one hand, and succession and duration on the other.

Next, I shall analyse a slightly modified version of the same claim, according to which we experience temporal passage by virtue of the fact that our experiences of ordinary change have a dynamic or "flowing" phenomenal character.

\section{Experiencing the Phenomenal Flow}

Closely related to the intuition that we experience passage by virtue of experiencing change, is the intuition that change 'feels dynamic' or 'flowing' in experience. The intuition appeals to the phenomenal character of change experiences: 'what it is like' to experience ordinary change is supposed to be in some sense dynamic. To clarify: the claim is that the content of the experience $\left(\mathrm{F}(a)\right.$ at $\mathrm{t}_{1}$ and $\mathrm{G}(a)$ at $\left.\mathrm{t}_{2}\right)$ is neutral as to whether the perceived change is A-change or B-change, but that the 'phenomenal feel' of change experiences is in some sense dynamic. Whether or not such a suggestion makes sense depends on the theory of perception one supports. Strong representationalists hold that the phenomenal character of experiences is identical to, or at least supervenes on, the representational content. ${ }^{22}$ Recall that we are (for now) focussing on experiences of change with a content that is mute as to whether the change represented is A- or B-change. All that a strong representationalist could infer from the dynamic character of experiences of change is that change in general feels dynamic in experience, but she could not infer as to whether this feature is a feature of experienced A-change, B-change, or of all types of change in experience. Given that the content is neutral as to whether time passes or not, the character would also be neutral with regards to time's passage.

Weak representationalism allows for qualitative divergence between phenomenal character and content. ${ }^{23}$ On such views, one might think an experience of change that is content-wise neutral as to whether it represents A- or B-change, still "feels" like A-change, rather than B-change. Even if this were the case though, there would be no reason to think that such an experience told us anything about the nature of change and time at all. Phenomenal character, thus understood, is not a representational feature of experiences. Suppose the weak representationalist thinks that we have evolved in such a way that the phenomenal character of our experiences qualitatively 'matches' what is represented in experience. ${ }^{24}$ She could then argue that such a correspondence would allow us to be aware of change as A-change (even if the way the change was represented would be neutral in this respect). Let us assume for a moment that there was such a match. Could I infer from my experience of change that the change I am experiencing is A-change and not B-change? The answer must be negative. Although there is a metaphysical difference between the two changes-Achange is tensed and necessitated by the fact that time passes, B-change not—one would need a very good argument to get from there to a phenomenal difference between the two changes as experienced. This brings us to a further difficulty: we can never be in the situation to experientially compare A-changes with B-changes, for either time passes, in which case all change is A-change, or it doesn't, in which case all change is B-change. This being the case, we cannot even know what it would be like to experience A-change rather than B-change. If it was possible to compare A-changes with $\mathrm{B}$-changes in experience, and experiences of the former would have a distinctive A-phenomenal dynamic character, then we might (assuming the matching hypothesis) be aware

\footnotetext{
${ }^{22}$ See for example Dretske (1995), Tye (2000) and Byrne (2001).

${ }^{23}$ See for example Block (1990).

${ }^{24}$ Laurie Paul was discussing (and ultimately rejecting) a similar view in her talk 'Experience and the Direction of Time' at the Workshop 'Temporal Experience' for the Network of Sensory Research in Toronto 2013.
} 
of the change as A-change. But to infer from the fact that there is a metaphysical difference between the two kinds of change that there would also be a matching phenomenal difference, is to put the cart before the horse.

Precisely because there are no contrast cases between A-experiences and B-experiences, passage defenders often motivate their intuition with what they take to be an analogous contrast, the phenomenal contrast between experiences of spatial variation and experiences of change. Consider for example the phenomenal difference between seeing a chameleon changing from red to green and seeing a chameleon that is red and green striped. Once the intuition about change seeming dynamic in experience is bought, the thought is presumably that change seems dynamic because it is brought about by temporal passage, whereas spatial variation seems static because space is static. And, more, if time were static just as space, and change just a series of static events, then experiences of change would be more like experiences of spatial variation. But the analogy is flawed: the phenomenal contrast between spatial variation and change does not carry over to the phenomenal contrast between A-change and B-change. For one might also think that all temporal experiences have a dynamic character by virtue of being temporal experiences, whereas all spatial experiences have a static character by virtue of being spatial experiences. In other words, change experiences could have the dynamic character they have because they are experiences of variation in time (rather than in space), and not because the change experienced is A-change (rather than B-change). These two explanations, it seems, stand on an equal footing. As long as we cannot contrast A-change experiences with B-change experiences, there is no good way to conclusively decide which explanation is better. And given that it is impossible to contrast A-experiences with B-experiences, it is wise to abandon the thought that we are aware of time's passage by virtue of having experiences of change that feel dynamic.

In the next and last section I will look at the suggestion that we experience temporal passage by virtue of experiencing (successive) events as present.

\section{Temporal Passage and Presentness}

Some people think that experiencing temporal passage just is (read: is nothing more than) experiencing events as present. ${ }^{25}$ Roughly speaking, the idea is presumably that experiences of events as present amount to experiences of temporal passage because temporal passage consists in

\footnotetext{
${ }^{25}$ Le Poidevin mentions this view (Le Poidevin 2007, p. 77), but it is also discussed among others by Mellor (1981, 1998), Callender (2008) and Prosser (2007).
}

times being (successively) present. I shall give three arguments against this view:

5.1 The argument against visibility

5.2 The argument against vividness*

5.3 The argument against tensed perceptual content

First I argue that it is hard to see what experiences of presentness are supposed to be like, for there is no property presentness can be contrasted with in visual experience. Second, I argue that if presentness was experientially represented as a kind of vividness, then these experiences would not be best explained by the fact that some things are really present in the relevant, that is, A-theoretic sense. And third, I point out that to have tensed perceptual content is not sufficient for an experience to be an experience of tensed facts.

Before I begin, two issues have to be clarified, one about terminology and one about temporal perception. Concerning the terminology, it will be especially important to keep the distinction between the A-theoretic and the B-theoretic notion of presentness in mind. For A-theorists, presentness is an objective (that is mind-independent) property. For B-theorists, presentness is an indexical notion analogous to the spatial indexical 'here'. Contrary to A-theoretic presentness, B-theoretic presentness is perspective dependent: to predicate presentness of something is to predicate a relation of simultaneity between that thing and something else: a date, a speaker, an event. To avoid misunderstandings, I shall call the A-theoretic notion of presentness 'A-presentness' or 'A-present'. The terms 'B-presentness' or ' $B$-present' are used for the B-theoretic notion of presentness and I shall just say 'present' or 'presentness' when I wish to stay neutral between these notions.

Second, I have introduced the view under discussion as the view that to experience temporal passage is to experience events as A-present. More precisely it should be stated as the view that to experience temporal passage is to experience a succession of events as successively A-present. It would be incoherent to hold that to visually represent temporal passage is to visually represent a single event being present. For time to pass, there needs to be a change of what is present, and one might then ask how it is possible to represent successive events in a single perceptual experience. Thus, similarly as with the argument from folk intuition, the argument here requires a realist account of temporal perception to begin with. I shall thus assume, for the sake of the argument, that some such theory is correct.

The argument I aim to prove wrong is that we experience temporal passage by virtue of experiencing events being successively A-present. That said, we can simplify our strategy somewhat and just argue against the claim that we have experiences as of events as A-present. If we do not experience events as A-present, we do not experience 
events being successively A-present either. I call the argument I am opposing the Argument from Presentness $(A f P)$ :

(AfP) (1)

1. We have experiences as of events as A-present.

2. The best explanation for these experiences is that some things are A-present.

3. Therefore some things are A-present.

4. Some things are A-present, only if time passes.

5. Therefore time passes.

AfP is the view that one can infer from experience that some things are A-present, and that A-presentness entails temporal passage. The first of my three arguments rejects the first premise of AfP, the last two turn against the second.

\subsection{The Argument Against Visibility}

Suppose that on a clear night you are out with a telescope to look at the stars. With you is a friend who knows a lot about stars. He is pointing the telescope towards the sky and tells you to look into it. You see two stars. 'The one on the left does not exist anymore' your friend explains, 'it is only because it is so far away and the light takes so long to reach us, that we still see it'. You are amazed because it looks just like the other star. It seems as though you see both stars as A-present, although you know that one of them does not exist anymore. ${ }^{26}$

One mistaken conclusion that someone might draw from this is that since past events appear through the telescope in the same way as present events, nothing looks like it has presentness. This is the view that Skow (unfairly, I think) ascribes to Hestevold:

Hestevold concludes: "since past events [or past things] appear through the telescope to an observer in the same way that present events [or things] appear to the observer," nothing looks like it has presentness. (Skow 2011 370). ${ }^{27}$

I agree with Skow that this is not a good argument. The fact that one seems to see both stars as A-present, although one of them does not exist anymore, does not show that neither of them looks A-present. It could be that both stars are visually represented as A-present, but that (at least) one of the experiences is illusory. If you seem to see two red apples, although one of them is actually green, it does not follow that neither of them looks red. It rather shows that you experience both apples as red, and that in one case

\footnotetext{
${ }^{26}$ A similar example is found in Mellor (1998), Le Poidevin (2007) and Hestevold (1990).

27 Skow refers to Hestevold (1990).
}

your experience is mistaken (cf. Skow 2011). It would be unfair to interpret the example in this way though. What it means to show is that everything, even stars that do not exist anymore, is (when it is experienced at all) represented as A-present in experience. We do not have visual experiences as of past or future events as past or as future. Even if what is seen is actually past, we see it as A-present. ${ }^{28}$ There does not seem to be anything in the visual properties of a photograph, say, that shows us that the depicted scene is past. In fact, due to the time lag in perceptual experience, everything that we see is past. But we still seem to see it as A-present and not as past. As Mellor puts it,

[o]ur reasons for thinking we cannot see the future [or the past] rest not on observation but on theory. (1998, p. 16)

In other words, we cannot contrast A-presentness from anything else in visual experience. ${ }^{29}$ But if everything is experienced as A-present, then it is hard to get a grip on what something has to look like in order to look A-present. An analogy might help. We can understand what green looks like by looking at two different green objects, say a cloverleaf and a grasshopper. Although the objects are very different, they are also similar in one salient respect-they are both green. If everything looked green, then it would be hard to grasp the respect in which those objects are similar (cf. Skow 2011, p. 366). The idea behind this is that phenomenal properties, properties that are represented in experience, have a discriminatory function (see also (Prosser 2007)). We learn what it means to look in a certain way, by distinguishing objects on the basis of their visual differences. In other words, to understand what green looks like, one has to learn what green does not look like. An analogous point could be made about A-presentness: to understand what A-presentness looks like, one needs to understand how A-presentness does not look like. But if I experience everything as A-present, then I cannot know what A-presentness looks like, for I cannot know what A-presentness does not look like. If we cannot contrast experiences as of A-presentness from experiences as of pastness or futurity, then experiencing something as A-present just seems to boil down to experiencing something fullstop. Le Poidevin agrees:

\footnotetext{
${ }^{28}$ A similar point could be made about future events. If we were able to see the future, we would still represent it as present. Mellor has an example of this sort involving a magic crystal ball. Whatever future scene is presented to you in the magic ball, it still looks present to you. But we could not conclude from this that it is present (Mellor 1998, p. 16).

${ }^{29}$ Le Poidevin makes a similar point (2007, p. 78).
} 
To perceive something as [A-]present is simply to perceive it: we do not need to postulate some extra item in our experience that is 'the experience of [A-] presentness' (Le Poidevin 2011). ${ }^{30}$

Here is another way to put it. If two experiences seem qualitatively the same to you, even though they are supposed to be different with respect to some property $\mathrm{F}$, then it is safe to assume that we do not represent $F$ in experience. If you want to know whether you can see a certain colour or not, then you make a test by looking at some spectrum that includes the colour and another spectrum which doesn't include it. If you fail to notice the difference, then it is safe to assume that you cannot represent that particular colour in experience.

That said, somebody might argue that we can contrast experiences as of A-presentness from memory experiences as of past events or from imaginings as of future ones. ${ }^{31}$ Whatever quality is phenomenally present in perceptual experience but not in memory or imaginings, is how A-presentness is represented in perceptual experience. I will come to that objection in the next sub-section.

\subsection{The Argument Against Vividness}

Against the view that A-presentness is not visible because it cannot be phenomenally contrasted from anything, one might raise the following objection. It is not true that we cannot contrast experiences as of A-presentness from anything. Memory experiences represent things as past. Imaginative experiences can represent things as future. Just because we perceptually represent everything as A-present, it does not follow that we cannot know what it is for something to look A-present. We can contrast the way things look in perceptual experience from the way things look in our memories or future orientated imaginings.

If this objection is to be successful, the opponent has to show first that the phenomenal difference between my visual experiences and my memories or my imaginings about the future is due to the fact that my perceptual experiences represent A-presentness, whereas my memories and my imaginings don't. If A-presentness is represented in visual experience, then it should be visible (cf. Skow 2011, p. 369). Suppose at time $t_{1}$ you are looking at a green tomato and at time $t_{2}$ you are looking at a red tomato and you remember looking at a green tomato. Now, if A-presentness was a phenomenal property, then you should be able to see that the tomato is red, round and A-present, whereas in your memory, you should represent a tomato that is green and round, but as lacking the quality of

\footnotetext{
${ }^{30}$ See also Hestevold (1990, p. 542), Le Poidevin (2007), (Paul 2010) on the same point.

${ }^{31}$ Fiona Macpherson brought this point to my attention.
}

A-presentness. However, I am not aware of such a quality represented in visual experience. A-presentness does not seem to be some additional visible feature that distinguishes the perceived tomato from the remembered one. A-presentness, it seems, is not a phenomenal property.

This is too quick, my opponent might complain. There is after all some phenomenal difference between one's visual perceptual experiences and one's pictorial representations of the past in memory (or respectively one's imaginings of the future). Perceptual experiences seem to have a special lucidity or vividness about them that memories or imaginings lack. Maybe we represent A-presentness as a kind of vividness in perceptual experience. Maybe this is the way A-presentness looks-it makes whatever is experientially represented vivid. Let us grant for the sake of the argument that A-presentness is visually represented as a kind of vividness in experience. Let us also grant that the kind of vividness that represents A-presentness in experience is a unique kind of vividness that all and only present experiences have. I shall call it vividness*. The idea then is that whatever is perceptually experienced as A-present, is represented as looking vivid*. Only present perceptual experiences, but not memories or imaginings look A-present, by virtue of looking vivid*.

To show why this suggestion wont help the dynamic theorist, I will have to appeal to the overall structure of the argument. The first premise of AfP says that we have experiences as of events as A-present. If A-presentness looks like vividness* in experience, we can change the first premise such that we have experiences as of events as vivid*. To get from that premise to the conclusion that time passes, one needs to argue from the experience of vividness* to the conclusion that some things are A-present. From the claim that some things are A-present, a further argument is needed to show that A-presentness entails temporal passage.

The Argument from Presentness (AfP) (2)

1. We have visual experiences as of events as vivid*.

2. The best explanation for these experiences is that some things are A-present.

3. Therefore some things are A-present.

4. Some things are A-present only if time passes.

5. Therefore time passes.

(1) is the position that is assumed. I will assume the truth of (4), although one might think that a 'frozen' static A-world is a viable position in logical space. ${ }^{32} \mathrm{~A}$ discussion about the tenability of such non-standard A-theoretic views would lead us too far astray though. Note that (1-3) is an

\footnotetext{
${ }^{32}$ Fine writes for example: 'Even if presentness is allowed to shed its light upon the world there is nothing in [this] metaphysics to prevent that light from being 'frozen' on a particular moment of time. (Fine 2005: 287).
} 
argument analogous to AfE, the Argument from Experience. The structure of AfE imposes a constraint on the experience of temporal passage. However passage is experientially represented, the experiential content must be best explained by the fact that time passes. The same goes for AfP: however A-presentness is experientially represented, the experience must be best explained by the fact that something instantiates A-presentness. Something is only best explained by some fact $\mathrm{F}$ (or, depending on one's view of facts, by some theory involving F), if there aren't any better or equally good explanations than $\mathrm{F}$ at hand. I suggest that, all things considered even, a necessary condition for the content of one's experience to be best explained by the fact that time passes, or that A-presentness is instantiated, is that the experience must be such that it could not be accurate if time did not pass, or A-presentness were not instantiated. ${ }^{33}$

\section{(BestEx)}

For an experience Ex to be best explained by the fact that $\mathrm{p}$, it must be the case that, all things considered even, Ex could not be accurate if not $p$.

(BestEx) is a necessary condition for (the content of) any experience to be best explained by the fact that time passes (or that A-presentness is instantiated). For suppose temporal passage was visually represented in such a way that one's experience could be accurate if time passed, but also if time did not pass. In that case, it would be false to say that the fact that time passes is the best explanation for one's experience, even if those experiences were accurate. ${ }^{34}$ And analogously with experiences that are to be best explained by the fact that A-presentness is instantiated.

According to (1), A-presentness is represented as vividness* in visual experience. Applying (BestEx), the question is: Could anything be accurately represented to look vivid* even if there were no A-presentness properties? There is no prima facie reason why this could not be the case. One's visual experience of some event E as vivid* could be accurate if $\mathrm{E}$ was B-present. An event is B-present when it occurs at the same time as one's experience of it. That is, a subject $\mathrm{S}$ might accurately experience an event as

\footnotetext{
$\overline{33}$ I insert the 'all things considered even' clause because one might think that if there are other things than the occurrence or lack of passage which differ between a static and a dynamic world, than these might also be factors in explaining the experience. In that case, the fact that time passes would not necessarily be the best explanation for the experience that time passes. Analogously with A-presentness. Many thanks to Alexander Skiles for making this point.

34 Note, though, that (BestEx) is not a sufficient condition for an experience to be best explained by time's passage, for an illusion or hallucination of temporal passage could not be accurate in a static world either. The AfE/AfP defender also needs to say that an explanation that takes experiences to be veridical is generally a better explanation than one that resorts to illusions and hallucinations.
}

vivid*, when it occurs at the same time as S's experience of it. ${ }^{35}$ If so, then we can give a competing explanation to the A-theorist's ${ }^{36}$ :

1. We have visual experiences as of events as vivid*.

2. The best explanation for these experiences is that some events are B-present.

3. Therefore some events are B-present.

The alternative explanation offered is that a subject $\mathrm{S}$ experiences some events as vivid*, because some events are B-present, that is, occur at the same time as $S$ 's experience of it and B-presentness looks like vividness* in experience. A-theorists could still argue that this is a worse explanation than the explanation that some things are A-present. But it is hard to see how without begging the question. In other words, the A-theorist fails to argue for the existence of A-present things from experiences as of vividness*. If nothing is A-present, then there is nothing that entails that time passes. I conclude that, even if A-presentness was represented in visual experience as vividness*, we could not infer from these experiences that time passes. Next, I shall discuss a very different way in which one could be said to represent A-presentness in experience.

\subsection{The Argument Against Tensed Perceptual Content}

Some people think that to represent A-presentness in experience is just to have experiences with perceptual contents that are best expressed by tensed propositions, as in 'the rhino is (A-presently) yawning'. To this I will only say that it is a very contested point whether or not perceptual contents are tensed or not. ${ }^{37}$ I will, however, not go further into the debate because there is a more important point to be made. It is one thing for perceptual content to be expressed by a tensed proposition, and another thing for that proposition to have tensed truthmakers. Just as the B-theorist can deny that tensed propositions have tensed truthmakers, she can deny that perceptual contents expressed by tensed propositions

\footnotetext{
35 Strictly speaking, these experiences would be illusory, due to the time lag in experience. According to Butterfield though, we can almost always ignore the temporal delay. If the process of observation is reliable, and the object is not (much) more than 1,000 m away, we can learn about the observed object's state at the time when we judge $i t$, not only at a previous time. This is not only due to the fact that the time lag is very short (Butterfield suggests 'half a second') but also because solid objects change very infrequently. (1984, p. 163).

36 Note that the analogous move is not open to the B-theorist in the case of the original argument AfE: That time does not pass cannot be the best explanation for one's experience as of events undergoing A-change for if time did not pass, there could not be A-change.

37 Hoerl (2009), Oaklander (1991) and Russell (1915) are among those which have explicitly denied that perceptual experiences should be described as having tensed content. Oaklander has since changed his mind about this, as evident in his article in this very volume.
} 
have tensed accuracy conditions. Thus, the B-theorist could say that if I see that the rhino is (A-presently) yawning, my experience is accurate, if and only if the rhino yawns at the same time as I am seeing it. She could thereby argue that the tensed form of the perceptual content merely represents that the event experienced occurs simultaneous with one's experience of it. In other words, to have a veridical experience with a content that is best expressed by a tensed proposition, does not imply that one perceives A-presentness or that time passes.

We cannot discriminate things as present in experience. Even if we could, we could not know from experience alone whether the presentness seen is A-presentness or B-presentness. We cannot, therefore, experience temporal passage by virtue of experiencing events as A-present.

\section{Conclusion}

Many philosophers have claimed that dynamic accounts of time have an intuitive advantage over static ones. I think that they have judged too fast. To have any force at all, I argued, the argument behind that claim needs to be one that derives from perceptual experience. Once we scrutinize the usual suspect experiences that are commonly held to be experiences of temporal passage, it turns out that none of them actually amounts to an experience of passage. As a consequence, it becomes ever more opaque what exactly an experience of passage is supposed to be. And although dynamic theorists can still search for other candidate experiences, their obvious intuitive advantage has, it seems, dissolved. I have not attempted to settle the question whether we experience passage or not once and for all. However, if it turns out that there are no other or better candidate experiences than those I have discussed here, then passage is not among the temporal features that we are aware of in experience. ${ }^{38}$ In that case, one might even question the need for A-theories in the first place (Prosser 2007). ${ }^{39}$

\section{References}

Bigelow J (1996) Presentism and properties. Philos Perspect 10:35-52 Block Ned (1990) Inverted earth. Philos Perspect 4:53-79

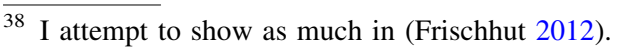

39 This paper has developed from my thesis, which has been financed by the Swiss National Science Foundation. I am indebted to many people who helped me to improve it. Among these are Fiona Macpherson, Fabrice Correia, Jonathan Lowe, Robin Le Poidevin, Barry Dainton, Kevin Mulligan and the eidos group in Geneva. I am especially grateful for fruitful discussions with Jan Almäng, Thomas Brouwer, Clare Mac Cumhaill, Natalja Deng, Craig French, Ghislain Guigon, Graham Peebles and Alex Skiles.
}

Broad CD (1938) An examination of McTaggart's philosophy, vol II. Cambridge University Press, Cambridge

Butterfield J (1984) Seeing the present. Mind 93(370):161-176

Byrne Alex (2001) Intentionalism defended. Philos Rev 110(2):199_ 240

Callender Craig (2008) The common now. Philos Issues 18(1): 339-361

Crisp Thomas M (2005) Presentism and "cross-time" relations. Am Philos Q 42(1):5-17

Crisp TM (2007) Presentism and the grounding objection. Noûs 41(1):90-109

Dainton BF (2000) Stream of consciousness: unity and continuity in conscious experience. Routledge, London

Dainton Barry (2008) The experience of time and change. Philos Compass 3(4):619-638

Dainton B (2010) Temporal consciousness. In: Zalta EN The Stanford Encyclopedia of Philosophy

Dainton B (2011) Time, passage and immediate experience. In: Callender C (ed) Oxford handbook of philosophy of time. Oxford University Press, Oxford

Deng $\mathrm{N}$ forthcoming. Our experience of passage on the B-Theory. Erkenntnis:1-14

Dennett DC (1991) Consciousness explained. Penguin, Harmondsworth Dretske F (1995) Naturalizing the mind. MIT Press, Cambridge

Fine K (2005) Modality and tense. Oxford University Press, Oxford

Foster J (1982) The case for idealism. Routledge and Kegan Paul, London

Frischhut Akiko (2012) The experience of temporal passage. University of Geneva/University of Glasgow, Geneva

Hestevold HS (1990) Passage and the presence of experience. Philos Phenomenol Res 50(3):537-552

Hoerl Christoph (2009) Time and tense in perceptual experience. Philos Impr 9(12):1-18

James W (1890) The principles of psychology. Dover, New York

Kelly SD (2005) The puzzle of temporal experience. In: Brook A (ed) Cognition and the brain: the philosophy and neuroscience movement. Cambridge University Press, Cambridge

Le Poidevin R (1991) Change, cause and contradiction. Macmillan, Basingstoke

Le Poidevin R (1996) The new theory of time. Int Philos Q 36(1):111-112

Le Poidevin R (1998) Questions of time and tense. Oxford University Press, Oxford

Le Poidevin R (2007) The images of time: an essay on temporal representation. Oxford University Press, Oxford

Le Poidevin, R (2011) The experience and perception of time. In Zalta EN (ed) The Stanford encyclopedia of philosophy

Le Poidevin R, Mellor DH (1987) Time, change, and the 'indexical fallacy'. Mind 96(384):534-538

Mabbott JD (1951) Our direct experience of time. Mind 60(April): $153-167$

Mabbott JD (1955) The specious present. Mind 64(July):376-383

Markosian N (2004) A defence of presentism. In: Zimmerman D (ed) Oxford studies in metaphysics. Oxford University Press, Oxford

Maudlin T (2002) Remarks on the passing of time. Proc Aristot Soc 102(3):237-252

Maudlin T (2007) The metaphysics within physics. Oxford University Press, Oxford

McTaggart JME (1908) The unreality of time. Mind 17(68):457-474

McTaggart JME (1927) The nature of existence. Vol. II. Cambridge University Press, Cambridge

Mellor DH (1981) Real time. Cambridge University Press, Cambridge

Mellor DH (1998) Real time II. Routledge, London

Oaklander LN (1991) A defence of the new tenseless theory of time. Philos Q 41(162):26-38

Oaklander LN (1993) On the experience of tenseless time. J Philos Res 18:159-166 
Oaklander LN (2002) Presentism, ontology and temporal experience. R Inst Philos Suppl 50:73-90

Oaklander LN (2004) Absolute becoming and the myth of passage. Philo 7(1):36-46

Oaklander LN (2012) A, B- and R-theories of time: a debate. In: Barton A (ed) The future of the philosophy of time. Routledge, London

Paul LA (2010) Temporal experience. J Philos 107(7):333-359

Peacocke C (1992) A study of concepts. MIT Press, Cambridge

Percival P (2002) A presentist's refutation of Mellor's McTaggart. R Inst Philos Suppl 50:91-118

Plumer G (1985) The myth of the specious present. Mind 94(January):19-35

Price H (1997) Time's arrow and archimedes' point: new directions for the physics of time. Oxford University Press, Oxford

Priest G (2006) In contradiction: a study of the transconsistent. Oxford University Press, Oxford

Prior AN (1958) Time after time. Mind 67(266):244-246

Prior AN (1959) Thank goodness that's over. Philosophy 34(128):12-17

Prior AN (1967) Past present and future. Clarendon, Oxford

Prior AN (1968a) Changes in events and changes in things. In: Papers on time and tense. Clarendon Press, Oxford

Prior AN (1968b) Now. Noûs 2(2):101-119

Prosser S (2007) Could we experience the passage of time? Ratio 20(1):75-90

Prosser S (2012) Why Does Time Seem to Pass? Philos Phenomenol Res 85(1):92-116

Quine WV (1960) Word and object. The MIT Press, Cambridge

Reichenbach H (1947) Elements of symbolic logic. Dover, Macmillan Co

Russell B (1914) Our knowledge of the external world: as a field for scientific method in philosophy. Routledge, London
Russell B (1915) On the experience of time. Monist 25(2):212-233

Russell B (1940) An inquiry into meaning and truth. W.W. Norton \& Company, New York

Russell B (1948) Human knowledge: its scope and limits. George Allen \& Unwin, London

Schlesinger GN (1991) E pur si muove. Philos Q 41(165):427-441

Schuster MM (1986) Is the flow of time subjective? Rev Metaphys 39(4):695-714

Shoemaker S (1969) Time without change. J Philos 66(12):363-381

Siegel Susanna (2010) Do visual experiences have contents. In: Nanay B (ed) Perceiving the world. Oxford University Press, Oxford

Skow B (2011) Experience and the passage of time. Philos Perspect 25(1):359-387

Smart JJC (1949) The river of time. Mind 58(232):483-494

Smart JJC (1955) Spatialising time. Mind 64(254):239-241

Smith Q (1993) Language and time. Oxford University Press, Oxford

Tallant J (2009) Presentism and truth-making. Erkenntnis 71(3):407416

Tallant J (2010) Time for presence? Philosophia 38(2):271-280

Tallant $\mathbf{J}$ forthcoming. A sketch of a presentist theory of passage. Erkenntnis

Tye M (2000) Consciousness, color, and content, vol 113. MIT Press, Cambridge

Tye M (2003) Consciousness and persons: unity and identity. MIT Press, Cambridge

Williams DC (1951) The myth of passage. J Philos 48(15):457-472

Zeilicovici D (1981) Temporal becoming minus the moving-now. Noûs 23(4):505-524

Zimmerman DW (2005) The A-theory of time, the B-theory of time, and 'taking tense seriously'. Dialectica 59(4):401-457 